\title{
The effect of obesity on patient-reported outcome measures after minimally invasive transforaminal lumbar interbody fusion
}

\author{
Steven J McAnany, Samuel C Overley, Steve Andelman, Daniel Alicea, Jun S Kim, Robert K Merrill and Sheeraz A Qureshi* \\ Icahn School of Medicine at Mount Sinai- New York City, NY
}

\begin{abstract}
Background Context: Minimally Invasive Transforaminal Lumbar Interbody Fusion (MI-TLIF) is becoming an increasingly popular vehicle for lumbar fusion procedures. Data suggests that MI-TLIF results in decreased blood loss and operative time with lower complication rates and equivalent patient-reported outcome measures (PROMs) compared to open TLIF. However, literature has shown that obese patients have less improvement in PROMs and lower PROMs at final follow-up after lumbar spinal procedures. Purpose: To determine what effect, if any, body mass index(BMI) has on fusion rates and PROMs.
\end{abstract}

Study Design/Setting: Retrospective case-control series of a consecutive cohort of patients undergoing MI-TLIF by a single surgeon at an urban academic center. Patient Sample: 52 consecutive non-randomized patients undergoing MI-TLIF.

Outcome Measures: Oswestry Disability Index (ODI) version 2, 12-item Short-Form Health Survey (SF-12), and Euroqol-5D (EQ-5D) as well as radiographic fusion on CT scan. Methods: A retrospective review was performed for consecutive patients at a single center who underwent MI-TLIF. PROM data included ODI version 2, SF-12, and EQ-5D. Fusion rates were graded by two fellowship-trained neuroradiologists.

Results: A total of 52 patients from a single institution were reviewed. 33 patients had a BMI < 30, and 19 patients had a BMI > 30 . The radiographic fusion rate was found to be $45 \%$ in the non-obese group and $47 \%$ in the obese group ( $\mathrm{p}=1.0$ ). There was a statistically significant negative correlation between BMI and EQ$5 \mathrm{D}$ scores $(\mathrm{r}=-0.25, \mathrm{n}=52, \mathrm{p}=0.05)$ and $\mathrm{BMI}$ and $\mathrm{SF}-12$ scores $(\mathrm{r}=-0.44, \mathrm{n}=38, \mathrm{p}=0.006)$ at final follow-up. There was a moderately positive, though not significant, correlation between BMI and ODI ( $r=0.28, \mathrm{n}=38, \mathrm{p}=0.09)$.

Conclusions: Obese patients showed significantly lower post-operative EQ-5D and SF-12 scores and trended towards higher ODI scores. There was no correlation between fusion status and BMI. Obesity may be a positive predictor for lower PROMs following MI-TLIF.

Abbreviations: MI-TLIF: Minimally Invasive Transforaminal Lumbar Interbody Fusion, BMI: Body Mass Index, PROMS: PatientReported Outcome Measures, ODI: Oswestry Disability Index, SF12: Short-Form Health Survey, Q-5D: Euroqol-5D, CT: Computed Tomography

\section{Introduction}

The prevalence of obesity in the United States is exceedingly high with more than one-third of Americans identified as having a body mass index greater than 30 [1]. Multiple studies have linked obesity to high rates of low back pain and lumbar degenerative disc disease [24]. When compared to non-obese patients, obese patients undergoing surgical lumbar decompression have been shown to have greater rates of perioperative and postoperative complications, yet have demonstrated equivalent outcomes regarding improvement in pain and functional disability [5-12]. Thus, the obese patient presents a unique challenge to the treating physician as the benefits of lumbar surgery are weighed against the high rate of potential complications.

Open transforaminal lumbar interbody fusion (TLIF) is a proven and effective procedure to decompress the lumbar spine and achieve a solid fusion. More recently, minimally invasive techniques have been developed in order to minimize soft tissue dissection, perioperative blood loss, and post-operative pain. Minimally invasive transforaminal lumbar interbody fusion (MI-TLIF) has been shown to have similar rates of fusion and equivalent patient-reported outcomes when compared to open TLIF [13-18]. MI-TLIF has been proposed as an attractive option for treating lumbar degenerative disc disease in the obese population in order to minimize potential surgical complications.

Initial studies comparing open TLIF to MI-TLIF in obese patients have demonstrated comparable short-term outcomes regarding pain relief and functional improvement $[19,20]$. Furthermore, MI-TLIF has been reported to be associated with either decreased or equivalent rates of perioperative complications when compared to open TLIF [21-23]. Less is known regarding the long-term patient reported outcomes as

Correspondence to: Sheeraz A Qureshi, MD, 5 East $98^{\text {th }} \mathrm{St}, 4^{\text {th }}$ Floor, New York, NY 10029, Tel: 212-241-3909, Fax: 646-537-8535; E-mail: Sheeraz.Qureshi@mountsinai.org

Key words: euroqol 5D, lumbar interbody fusion, minimally invasive spine surgery, obesity, oswestry disability index, patient-reported outcome measures, short-form health survey

Received: October 03, 2015; Accepted: October 23, 2015; Published: October 26,2015 
well as rates of late post-operative complications.

The purpose of this study is to compare long-term patient reported outcomes and assess rates of post-operative complications in obese and non-obese patients undergoing MI-TLIF for lumbar spondylosis and spondylolistheis resulting in neurogenic claudication or radiculopathy to determine whether utilization of minimally invasive techniques confers a benefit to the obese patient.

\section{Materials and methods}

A retrospective review was performed for consecutive patients at a large metropolitan academic medical center who underwent MIS TLIF by a single surgeon between July 2011 and August 2013. The electronic medical record and paper charts were queried to retrieve data consistent with the study's inclusion criteria.

A standard MIS TLIF was performed in all cases. The patients were placed prone on a Jackson table with a chest roll used to increase lumbar lordosis. Using fluoroscopic localization, the pedicles above and below the level of pathology were identified. A $2-3 \mathrm{~cm}$ incision was made lateral the pedicle on the side of the pathology. Jamshidi needles were then placed in the pedicles at the appropriate level. Guide wires were then advanced under fluoroscopic imaging. Following sequential dilation, an $18 \mathrm{~mm}$ tubular retractor was placed and docked on the superolateral aspect of the facet at the disc space. The projection of the dilator tube was confirmed on lateral fluoroscopy, aiming for the inferior and superior borders of the tube corresponding to the disc space without overlapping the superior aspect of the pedicle below the disc space of interest. A partial facetectomy is performed on the ipsilateral side with removal of the medial edge of the pars, lamina, and the medial facet joint. To decompress the contralateral side, the tubular retractor was medialized to allow undercutting of the contralateral lamina. The facet joint is removed until the medial wall of the pedicle can be palpated. Ligamentous flavum is removed, the epidural veins overlying the disc space are coagulated and the traversing nerve root is retracted medially. The disc space is then entered and prepared with the use of rongeurs, currettes, and disc space shavers. Trial interbody cages were inserted until appropriate tension was achieved. Demineralized bone is placed anterior within the disc space followed by impacted of the final PEEK interbody cage containing recombinant human bone morphogenetic protein- $2^{1}$ followed by placement of more demineralized bone posterior to the cage. Percutaneous pedicle screws are then placed over the guide wires following appropriate tapping. Once all pedicle screws are placed, a rod is placed percutaneously and secured with end caps after compressing.

All patients underwent an initial trial of non-operative care including activity modification, physical therapy, anti-inflammatory medications, opioid analgesics, or epidural injections for at least 3 months. Operative indications included degenerative spondylosis or spondylolisthesis resulting in central or foraminal stenosis, radiculopathy or neurogenic claudication, and failure of non-operative management. Patients were excluded if they had surgery for tumor, caudal equina, or infection.

Epidemiological variables were recorded including: sex, age, BMI, medical comorbidities, and smoking status. Radiographical data including plain radiographs and computed tomographic (CT) scans were reviewed by two fellowship-trained neuroradiologists. Final determination of fusion was performed on the CT scan obtained at the

${ }^{1}$ Off label use of recombinant human bone morphogenetic protein-2 two year follow-up. For the purposes of this study, fusion was defined as evidence of boney bridging from endplate to endplate within the cage as well as boney bridging lateral to the cage and in the anteroposterior plane. If a fusion mass did not meet all of the criteria, it was deemed to not be fused.

Prospectively recorded outcomes data included Oswestry Disability Index (ODI) version 2, 12-item Short-Form Health Survey (SF-12), and Euroqol-5D (EQ-5D) were collected post-operatively at the two year follow-up appointment and were used for analysis in this study

Graphpad Prism v6.5 (La Jolla, CA, USA) was utilized for statistical analysis with independent sample $\mathrm{T}$ test for continuous variables and Fisher's exact test for categorical data. Pearson's r correlation coefficient was used to measure the degree of association between independent, normally distributed variables. A P-value $<0.05$ was used to denote statistical significance.

\section{Results}

\section{Patient characteristics and demographics}

A total of 52 patients from a single institution were reviewed. Patient characteristics and demographics can be found in Table 1. Obesity in this study was defined as a BMI greater than 30 . Thirty-three patients had a BMI less than 30 , and 19 patients had a BMI over 30. Of those who were obese, patients were characterized as morbidly obese with a BMI greater than 35 . The average age in the non-obese group was $58.44 \pm 2.29$ as compared with $56.50 \pm 2.04$ in the obese group ( $\mathrm{p}=0.58$ ). BMI averaged $23.53 \pm 0.52$ in the non-obese group and 35.19 \pm 0.98 in the obese group $(\mathrm{p}<0.001)$. There was a statistically higher rate of hypertension found in the obese group ( $74 \%$ versus $48 \%$; $\mathrm{p}=0.003$ ). There was no difference in the two groups with respect to diabetes, smoking history, or number of vertebral level involved. There were no peri-operative complications in either group.

\section{Obesity and fusion}

Overall the radiographic fusion rate was found to be $45 \%$ in the non-obese group and $47 \%$ in the obese group $(\mathrm{p}=1.0)$. A Pearson product-moment correlation coefficient was computed to assess the relationship between BMI and radiographic fusion. There was a weakly

Table 1. Patient characteristics.

\begin{tabular}{|c|c|c|c|}
\hline Characteristics & Non-obese & Obese & p Value \\
\hline n & 33 & 19 & \\
\hline Age (y) & $58.44 \pm 2.29$ & $56.50 \pm 2.04$ & 0.58 \\
\hline Body mass index* & $23.53 \pm 0.52$ & $35.19 \pm 0.98$ & $<0.0001$ \\
\hline Hypertension* & $16(48 \%)$ & $14(74 \%)$ & 0.003 \\
\hline Diabetes & $4(12 \%)$ & $5(26 \%)$ & 0.25 \\
\hline Smoking history & $3(9 \%)$ & $2(11 \%)$ & 1 \\
\hline No. of vertebral levels involved & $1.27 \pm 1.0$ & $1.22 \pm 1.0$ & 0.75 \\
\hline $\mathbf{1}$ & 27 & 14 & \\
\hline $\mathbf{2}$ & 5 & 5 & \\
\hline $\mathbf{3}$ & 1 & 0 & \\
\hline Radiographic fusion & $15(45 \%)$ & $9(47 \%)$ & 1 \\
\hline
\end{tabular}

Table 1 represents the demographics of all patients included in the study as well as any statistical significance that existed between the obese and non-obese cohorts. *Significant values 
positive correlation between the two variables, $\mathrm{r}=0.089, \mathrm{n}=52, \mathrm{p}=0.53$. However, this correlation failed to reach statistical significance.

\section{Obesity and clinical outcomes}

A Pearson product-moment correlation coefficient was computed to assess the relationship between BMI and EQ-5D. Fifty-two patients provided post-operative EQ-5D surveys. There was a statistically significant negative correlation between the two variables, $r=-0.25$, $\mathrm{n}=52, \mathrm{p}=0.05$. A scatterplot summarizes the results (Figure 1) Overall, there was a weak to moderate, negative correlation between BMI and EQ-5D. Increases in BMI were correlated with decreases in EQ$5 \mathrm{D}$ scores. A Pearson product-moment correlation coefficient was computed to assess the relationship between BMI and SF-12. Thirtyeight patients provided post-operative SF-12 surveys. There was a statistically significant negative correlation between the two variables, $\mathrm{r}=-0.44, \mathrm{n}=38, \mathrm{p}=0.006$. A scatterplot summarizes the results (Figure 2). Overall, there was a strong, negative correlation between BMI and

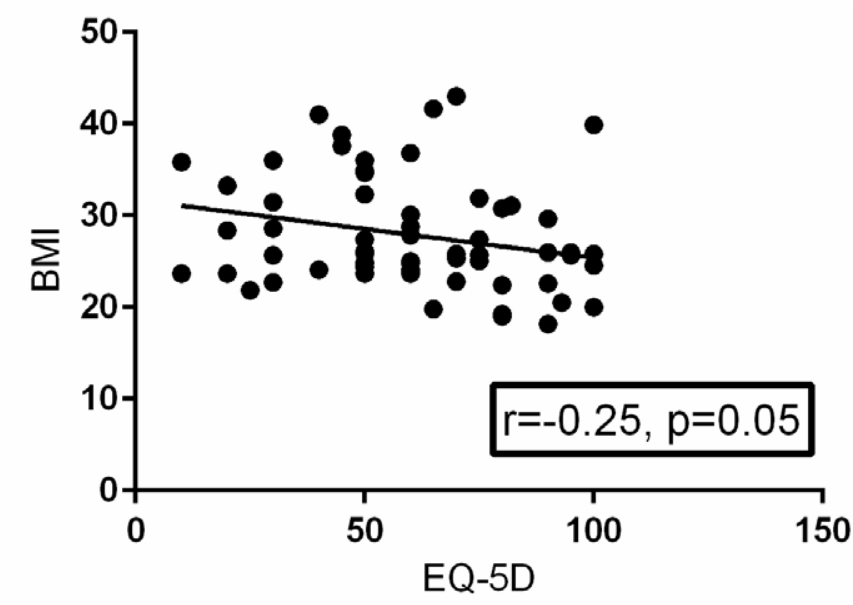

Figure 1. Scatterplot with a best-fit trendline summarizing the relationship between BMI and post-operative EQ-5D surveys from 52 patients. There is a statistically significant negative correlation between BMI and post-operative EQ-5D with a p-value of 0.05 . $R=$ the Pearson product-moment correlation coefficient.

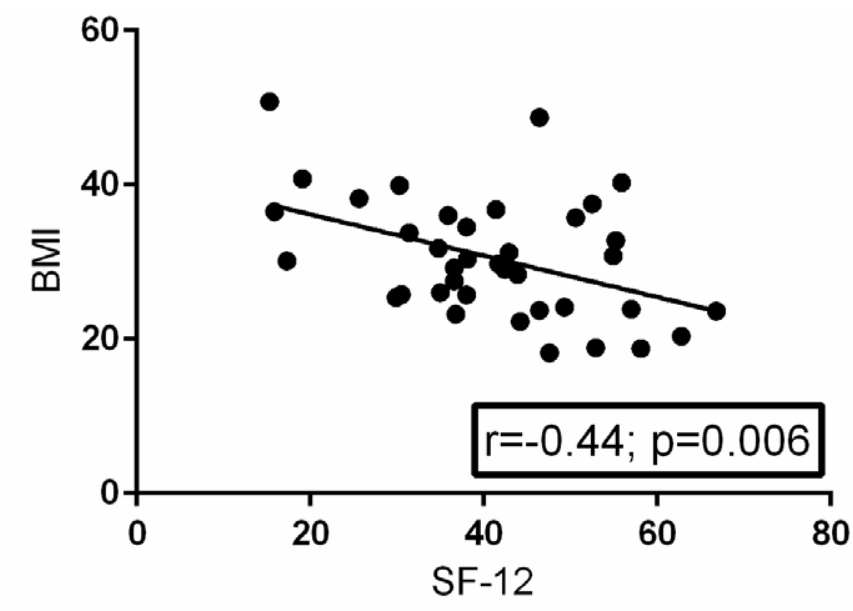

Figure 2. Scatterplot with a best-fit trendline summarizing the relationship between BMI and post-operative SF-12 surveys from 38 patients. There is a statistically significant negative correlation between BMI and post-operative SF-12 with a p-value of 0.006 . R=the Pearson product-moment correlation coefficient.

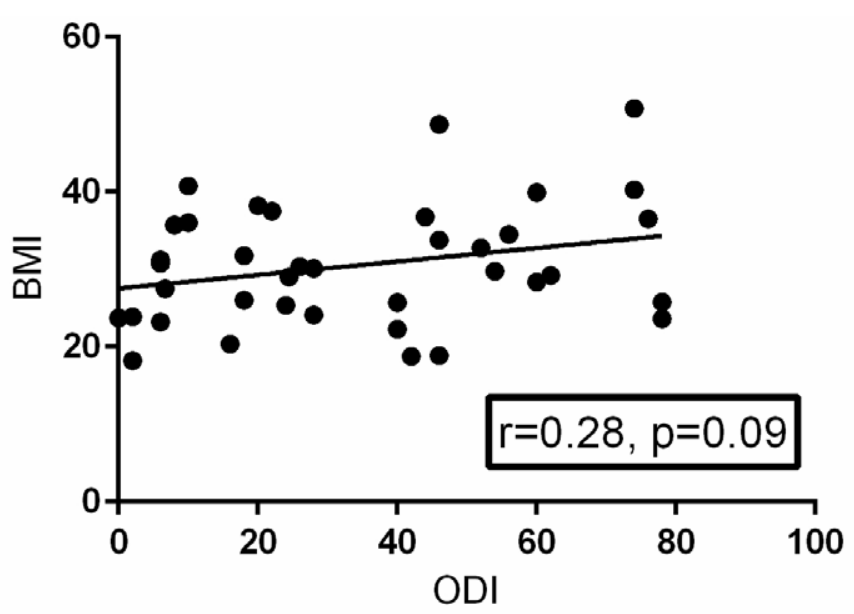

Figure 3. Scatterplot with a best-fit trendline summarizing the relationship between BMI and post-operative ODI surveys from 52 patients. There is positive correlation between BMI and post-operative ODI that is not statistically significant with a p-value of 0.09 . $\mathrm{R}=$ the Pearson product-moment correlation coefficient.

SF-12. Increases in BMI were correlated with decreases in SF-12 scores.

A Pearson product-moment correlation coefficient was computed to assess the relationship between BMI and ODI. Fifty-two patients provided post-operative ODI surveys. There was a moderately positive correlation between the two variables, $\mathrm{r}=0.28, \mathrm{n}=38, \mathrm{p}=0.09$. A scatterplot summarizes the results (Figure 3). Overall, there was a moderate, positive correlation between BMI and ODI. Increases in BMI were correlated with increased in ODI scores. This correlation failed to reach statistical significance, though it trended towards a significant value $(\mathrm{p}=0.09)$.

\section{Discussion}

Obesity remains a significant clinical concern as its prevalence is steadily rising and the management of these patients presents challenges to both the surgeon and anesthesia team. Currently over one-third of the United States'population is obese [24]. There is a growing body of literature that supports the notion that there is a higher risk for preoperative complications including greater risk for wound infections, airway-related complications, deep vein thrombosis, and pulmonary embolus [6,25-31]. Foley et al. [32] was the first to describe the MI-TLIF using tubular retractors via a muscle splitting approach to decrease the amount of soft tissue injury. Several authors have since shown MI-TLIF to be safe and efficacious with clinical and radiographic results comparable to the open TLIF approach $[17,33]$.

The current study is one of the first to directly compare the outcomes of MI-TLIF in obese and non-obese patients. The results of our study support the finding that obese patients report significantly decreased EQ-5D and SF-12 scores post-operatively as compared to non-obese patients. Our study also demonstrated a trend towards higher postoperative ODI scores for obese patients compared to non-obese patients, though it failed to reach statistical significance. The current study showed no difference in radiologic fusion rates between obese and non-obese patients at an average of 2 years follow-up. Additionally, our statistical analysis revealed no correlation between ODI, EQ-5D, or SF-12 and fusion status. Therefore it is unlikely that radiographic fusion status is a major determinant in short-term PROMs in nonobese or obese patients. And while it has been reported that there is 
a higher complication rate and associated morbidity in obese patients undergoing spine surgery, this was not shown in the present study. There were no complications in either group. It is possible that the obese patients have a lower starting pre-operative outcome state, and even if proportional gains are made, their post-operative improvement will not have the same magnitude as seen in the non-obese population.

In general, most studies report clinical outcomes as a net change from the baseline pre-operative state. In several of these studies, it has been shown that MI-TLIF results in improved clinical outcomes from baseline $[3,34,35]$. Andreshak et al. examined a multitude of lumbar procedures (Microdiscectomies, laminectomies and fusions) and found no difference in clinical outcomes, operative time, blood loss or length of stay between obese and non-obese patients [36]. Similarly, Vaidya et al. reported on surgical parameters and clinical outcomes after open lumbar fusion in obese patients. They found that although surgical blood loss and peri-operative complications were significantly higher in obese patients, post-operative ODI was not affected by obesity [12]. Contradictory findings were published by Gepstein et al., where obesity was found to be a significant independent risk factor for worse preand post-operative VAS scores as well as Barthel indices (assessment of ability to perform ADLs) in patients undergoing open lumbar spine surgery. They also demonstrated a significant proportion of obese patients as reporting their satisfaction level following surgery as "very dissatisfied" [10]. Additionally, Djurasovic et al. demonstrated that although improvement in SF-36 PCS and ODI scores from baseline were equivocal in obese and non-obese patients after open lumbar fusion, the 2-year values for these clinical outcome parameters were significantly worse in the obese cohort [6].

With such contradiction in the current literature surrounding clinical outcome measures in the obese population following open lumbar fusion, we set out to determine whether a muscle splitting MIS approach to lumbar fusion in obese patients improves clinical outcomes. An MIS approach to the lumbar spine decreases iatrogenic soft tissue injury and theoretically improves dynamic muscular stabilization at an index level [17,37-41]. MIS techniques also pose several potential advantages for use in obese patients in terms of decreased incision length, blood loss, operative time, hospital stay and post-operative pain where abundant subcutaneous adipose tissue may necessitate a larger incision and dissection for adequate exposure when utilizing a traditional open approach. These advantages have been validated in several studies $[3,34,35]$.

The results of the SPORT trial further validate the findings in our study. Rihn et al. conducted an as-treated analysis of the SPORT study on treatment for lumbar disc herniation examining outcomes in an obese (> 30 BMI) cohort against non-obese controls. They found that obese patients showed significantly less improvement from baseline and lower final follow-up values for SF-36 and ODI when compared to non-obese controls. This was true in both the operative (lumbar microdiscectomy) and non-operative arms. Additionally, obese patients that were managed operatively demonstrated significantly less improvement and lower final follow up values in the Sciatica Bothersomeness and Low Back Pain Bothersomeness Indices [42]. Though seemingly at odds with other clinical studies [12,20,3436], this as-treated analysis of the SPORT study has the benefit of a prospective design with large samples from multiple geographic locals and medical centers and long-term follow up which affords favorable generalizability of its results to true values expected in clinical practice.

The present study has several limitations. Though we present a retrospective review of prospectively collected outcomes data following MI-TLIF, we do not have pre-operative values. While this eliminates our ability to compare improvement from baseline, we can extrapolate from existing literature that clinical outcome measurements do improve, to some extent, from baseline after MI-TLIF in obese patients. Additionally, while ascertaining quantitative improvement from baseline is an important and tangible outcome measure in lumbar spinal fusion, it is not the primary variable of interest in our study. Rather, we aim to demonstrate any difference that may exist in outcome scores at final follow-up between obese and non-obese patients following MI-TLIF. Our study is also relatively under-powered. Despite this, we were able to reach statistical significance for two of the of the three measured outcome variables in a single-surgeon, single-center continuous patient cohort. Additionally, BMI measurements were cross-sectional at the time of index procedure and were not measured longitudinally. Reassessment of BMI at various post-operative time points may help detect an effect, if one exists, of surgery on obesity and aid in our understanding of spinal pain as a deterrent to weight loss in obese patients [42]. However, according to current literature, $\mathrm{BMI}$ is not likely to change significantly following lumbar spine fusion. Vaidya et al. showed BMI actually increased by an average of $1.5 \mathrm{~kg}$ at an average follow up of 20 months [5]. Finally, BMI is a relatively imprecise indicator of obesity and other more accurate measurements such as skin fold thickness or body surface area may have represented a more precise value of obesity [42].

\section{Conclusions}

Lumbar spine surgery in obese patients represents a significant clinical burden and challenge for the spine surgeon. In this study, obese patients had lower EQ-5D and SF-12 scores at 2-year follow-up when compared with non-obese patient. However, fusion rates were not shown to be impacted by obesity status in this study.

\section{Authorship and contributorship}

Steven J McAnany MD, Samuel C OverleyMD,Steve Andelman MD, Daniel Alicea BS, Jun S Kim MD, Robert K MerrillBS, Sheeraz A Qureshi MBA, MD

\section{Acknowledgements}

None

\section{Funding information} industry

This study was not funded by any outside sources, grants, or

\section{Competing interests}

The authors declare that they have no competing interests.

\section{References}

1. Ogden CL, Carroll MD, Kit BK, Flegal KM (2014) Prevalence of childhood and adult obesity in the United States, 2011-2012. JAMA 311: 806-814. [Crossref]

2. Liuke M, Solovieva S, Lamminen A, Luoma K, Leino-Arjas P, et al. (2005) Disc degeneration of the lumbar spine in relation to overweight. Int J Obes (Lond) 29: 903 908. [Crossref]

3. Shiri R, Karppinen J, Leino-Arjas P, Solovieva S, Viikari-Juntura E (2010) The association between obesity and low back pain: a meta-analysis. Am J Epidemiol 171: 135-154. [Crossref]

4. Hangai M, Kaneoka K, Kuno S, Hinotsu S, Sakane M, et al. (2008) Factors associated with lumbar intervertebral disc degeneration in the elderly. Spine $J$ 8: 732-740. [Crossref] 
5. Buerba RA, Fu MC, Gruskay JA, Long WD 3rd, Grauer JN (2014) Obese Class III patients at significantly greater risk of multiple complications after lumbar surgery: an analysis of 10,387 patients in the ACS NSQIP database. Spine $J$ 14: 2008-2018. [Crossref]

6. Djurasovic M, Bratcher KR, Glassman SD, Dimar JR, Carreon LY (2008) The effect of obesity on clinical outcomes after lumbar fusion. Spine (Phila Pa 1976) 33: 17891792. [Crossref]

7. De la Garza-Ramos R, Bydon M, Abt NB, Sciubba DM, Wolinsky JP, et al. (2015) The impact of obesity on short- and long-term outcomes after lumbar fusion. Spine (Phila Pa 1976) 40: 56-61. [Crossref]

8. Gaudelli C, Thomas K (2012) Obesity and early reoperation rate after elective lumbar spine surgery: a population-based study. Evid Based Spine Care J 3: 11-16. [Crossref]

9. Kalanithi PA, Arrigo R, Boakye M (2012) Morbid obesity increases cost and complication rates in spinal arthrodesis. Spine (Phila Pa 1976) 37: 982-988. [Crossref]

10. Gepstein R, Shabat S, Arinzon ZH, Berner Y, Catz A, et al. (2004) Does obesity affect the results of lumbar decompressive spinal surgery in the elderly? Clin Orthop Relat Res: 138-144. [Crossref]

11. Patel N, Bagan B, Vadera S, Maltenfort MG, Deutsch H, et al. (2007) Obesity and spine surgery: relation to perioperative complications. J Neurosurg Spine 6: 291-297. [Crossref]

12. Vaidya R, Carp J, Bartol S, Ouellette N, Lee S, et al. (2009) Lumbar spine fusion in obese and morbidly obese patients. Spine (Phila Pa 1976) 34: 495-500. [Crossref]

13. Rodríguez-Vela J, Lobo-Escolar A, Joven E, Muñoz-Marín J, Herrera A, et al. (2013) Clinical outcomes of minimally invasive versus open approach for one-leve transforaminal lumbar interbody fusion at the 3- to 4-year follow-up. Eur Spine J 22: 2857-2863. [Crossref]

14. Dhall SS, Wang MY, Mummaneni PV (2008) Clinical and radiographic comparison of mini-open transforaminal lumbar interbody fusion with open transforaminal lumbar interbody fusion in 42 patients with long-term follow-up. J Neurosurg Spine 9: 560565. [Crossref]

15. Peng CW, Yue WM, Poh SY, Yeo W, Tan SB (2009) Clinical and radiological outcomes of minimally invasive versus open transforaminal lumbar interbody fusion. Spine (Phila Pa 1976) 34: 1385-1389. [Crossref]

16. Villavicencio AT, Burneikiene S, Roeca CM, Nelson EL, Mason A (2010) Minimally invasive versus open transforaminal lumbar interbody fusion. Surg Neurol Int 1: 12. [Crossref]

17. Schwender JD, Holly LT, Rouben DP, Foley KT (2005) Minimally invasive transforaminal lumbar interbody fusion (TLIF): technical feasibility and initial results. J Spinal Disord Tech 18 Suppl: S1-6. [Crossref]

18. Wu RH, Fraser JF, Härtl R (2010) Minimal access versus open transforaminal lumbar interbody fusion: meta-analysis of fusion rates. Spine (Phila Pa 1976) 35: 2273-2281. [Crossref]

19. Terman SW, Yee TJ, Lau D, Khan AA, La Marca F, et al. (2014) Minimally invasive versus open transforaminal lumbar interbody fusion: comparison of clinical outcomes among obese patients. J Neurosurg Spine 20: 644-652. [Crossref]

20. Wang J, Zhou Y, Feng Zhang Z, Qing Li C, Jie Zheng W, et al. (2014) Comparison of the clinical outcome in overweight or obese patients after minimally invasive versus open transforaminal lumbar interbody fusion. J Spinal Disord Tech 27: 202-206. [Crossref]

21. Park P, Upadhyaya C, Garton HJ, Foley KT (2008) The impact of minimally invasive spine surgery on perioperative complications in overweight or obese patients. Neurosurgery 62: 693-699. [Crossref]

22. Lau D, Ziewacz J, Park P (2013) Minimally invasive transforaminal lumbar interbody fusion for spondylolisthesis in patients with significant obesity. J Clin Neurosci 20: 80-83. [Crossref]

23. Lau D, Khan A, Terman SW, Yee T, La Marca F, et al. (2013) Comparison of perioperative outcomes following open versus minimally invasive transforaminal lumbar interbody fusion in obese patients. Neurosurg Focus 35: E10. [Crossref]

24. Flegal KM, Carroll MD, Kit BK, Ogden CL (2012) Prevalence of obesity and trends in the distribution of body mass index among US adults, 1999-2010. JAMA 307: 491497. [Crossref]

25. Aghi MK, Eskandar EN, Carter BS, Curry WT Jr, Barker FG 2nd (2007) Increased prevalence of obesity and obesity-related postoperative complications in male patients with meningiomas. Neurosurgery 61: 754-760. [Crossref]

26. Espejo B, Torres A, Valentín M, Bueno B, Andrés A, et al. (2003) Obesity favors surgical and infectious complications after renal transplantation. Transplant Proc 35: 1762-1763. [Crossref]

27. Lau D, Terman SW, Patel R, La Marca F, Park P (2013) Incidence of and risk factor for superior facet violation in minimally invasive versus open pedicle screw placement during transforaminal lumbar interbody fusion: a comparative analysis. $J$ Neurosurg Spine 18: 356-361. [Crossref]

28. Lynch RJ, Ranney DN, Shijie C, Lee DS, Samala N, et al. (2009) Obesity, surgica site infection, and outcome following renal transplantation. Ann Surg 250: 1014-1020. [Crossref]

29. Noun R, Riachy E, Ghorra C, Yazbeck T, Tohme C, et al. (2008) The impact of obesity on surgical outcome after pancreaticoduodenectomy. JOP 9: 468-476. [Crossref]

30. Rogde AJ, Gudbrandsdottir G, Hjelle KM, Sand KE, Bostad L, et al. (2012) Obesity is associated with an improved cancer-specific survival, but an increased rate of postoperative complications after surgery for renal cell carcinoma. Scand J Urol Nephrol 46: 348-357. [Crossref]

31. Patel N, Bagan B, Vadera S, Maltenfort MG, Deutsch H, et al. (2007) Obesity and spine surgery: relation to perioperative complications. J Neurosurg Spine 6: 291-297. [Crossref]

32. Kambin P (2004) Re: Foley KT, Holly LT, Schwender JD. Minimally invasive lumbar fusion Spine (Phila Pa 1976) 29: 598-599. [Crossref]

33. Park P, Foley KT (2008) Minimally invasive transforaminal lumbar interbody fusion with reduction of spondylolisthesis: technique and outcomes after a minimum of 2 years' follow-up. Neurosurg Focus 25: E16. [Crossref]

34. Rosen DS, Ferguson SD, Ogden AT, Huo D, Fessler RG (2008) Obesity and selfreported outcome after minimally invasive lumbar spinal fusion surgery. Neurosurgery 63: 956-960. [Crossref]

35. Tomasino A, Parikh K, Steinberger J, Knopman J, Boockvar J, et al. (2009) Tubular microsurgery for lumbar discectomies and laminectomies in obese patients: operative results and outcome. Spine (Phila Pa 1976) 34: E664-672. [Crossref]

36. Andreshak TG, An HS, Hall J, Stein B (1997) Lumbar spine surgery in the obese patient. J Spinal Disord 10: 376-379. [Crossref]

37. Isaacs RE, Podichetty VK, Santiago P, Sandhu FA, Spears J, et al. (2005) Minimally invasive microendoscopy-assisted transforaminal lumbar interbody fusion with instrumentation. J Neurosurg Spine 3: 98-105. [Crossref]

38. Ozgur BM, Yoo K, Rodriguez G, Taylor WR (2005) Minimally-invasive technique for transforaminal lumbar interbody fusion (TLIF). Eur Spine J 14: 887-894. [Crossref]

39. Scheufler KM, Dohmen H, Vougioukas VI (2007) Percutaneous transforaminal lumbar interbody fusion for the treatment of degenerative lumbar instability. Neurosurgery 60 : 203-212. [Crossref]

40. Schizas C, Tzinieris N, Tsiridis E, Kosmopoulos V (2009) Minimally invasive versus open transforaminal lumbar interbody fusion: evaluating initial experience. Int Orthop 33: 1683-1688. [Crossref]

41. Wang J, Zhou Y, Zhang ZF, Li CQ, Zheng WJ, et al. (2010) Comparison of one-leve minimally invasive and open transforaminal lumbar interbody fusion in degenerative and isthmic spondylolisthesis grades 1 and 2. Eur Spine J 19: 1780-1784. [Crossref]

42. Rihn JA, Kurd M, Hilibrand AS, Lurie J, Zhao W, et al. (2013) The influence of obesity on the outcome of treatment of lumbar disc herniation: analysis of the Spine Patient Outcomes Research Trial (SPORT). J Bone Joint Surg Am 95: 1-8. [Crossref]

Copyright: (C)2015 McAnany SJ. This is an open-access article distributed under the terms of the Creative Commons Attribution License, which permits unrestricted use, distribution, and reproduction in any medium, provided the original author and source are credited. 